BULLETIN Bulletin hispanique

HISPANIQUE Université Michel de Montaigne Bordeaux

$110-2 \mid 2008$

Varia

\title{
Rubén Darío, Crónicas desconocidas, 1901-1906
}

\section{Ricardo Sumalavia}

\section{OpenEdition}

\section{Journals}

Edición electrónica

URL: http://journals.openedition.org/bulletinhispanique/835

DOI: 10.4000/bulletinhispanique.835

ISSN: 1775-3821

\section{Editor}

Presses universitaires de Bordeaux

\section{Edición impresa}

Fecha de publicación: 1 diciembre 2008

Paginación: 727-728

ISBN: 978-2-86781-543-0

ISSN: 0007-4640

\section{Referencia electrónica}

Ricardo Sumalavia, «Rubén Darío, Crónicas desconocidas, 1901-1906 », Bulletin hispanique [En línea], 110-2 | 2008, Publicado el 26 junio 2012, consultado el 21 septiembre 2020. URL : http:// journals.openedition.org/bulletinhispanique/835; DOI : https://doi.org/10.4000/bulletinhispanique. 835 
siècle, je crois que les deux ouvrages, loin de s'exclure mutuellement, sont - pouvait-il en être autrement ? - complémentaires. Á moins que je ne me sois laissé moi-même abuser à mon corps défendant par les dissemblances que je viens d'évoquer...

René ANDIOC

Rubén Darío, Crónicas desconocidas, 1901-1906. Günter Schmigalle (ed.). - Berlin/Managua, Academia nicaragüense de la Lengua/Tranvía - Verlag Walter Frey, 2006, 596 p. : bibliografía, índice onomástico. - ISBN : 3.925867.98.8.

Para comprender cabalmente la obra de un autor no es suficiente la difusión y análisis de las obras más representativas del mismo. Y más aún si se trata de la obra de un escritor clave, como es el caso del nicaragüense Rubén Darío, quien a lo largo de su vasta producción literaria no sólo nos ha mostrado creativa y reflexivamente el período crítico y de desajustes de entre siglos (XIX y XX), sino que además nos ha enseñado a mirar de una manera distinta esa nueva realidad (que desde ese momento deberíamos llamar más bien realidades). Esto lo ha sabido muy bien el investigador Günter Schimigalle y por ello, durante varios años y con un meritorio esfuerzo, se dedicó a rescatar, recopilar y establecer con un juicio crítico una clasificación que permita a los lectores un adecuado internamiento en la amplia obra cronística de Darío. Años antes este investigador nos ofreció en cuatro volúmenes un amplio conjunto de las crónicas de mayor difusión del escritor modernista, reunidas bajo el título de La caravana pasa. El mérito de aquella edición, además de una clasificación temática rigurosa, es la detallada anotación de los textos. Si bien las notas son abundantes, en este caso no interrumpen la lectura, sino muy por el contrario, contextualizan, revisten y enriquecen cada crónica. Podemos afirmar que Günter Schimigalle practica notablemente la vieja tradición de la glosa.

En Crónicas desconocidas el aporte de este investigador (además de las más de mil notas en este tomo) es haber recuperado textos de Darío que aparecieron entre los años 1901 y 1906 en diario La Nación de Buenos Aires y que no habían sido recuperados ni por el autor ni por los futuros compiladores. Cabe resaltar que todas estas crónicas tienen como escenario la ciudad de París, lo cual marcará el tenor de su escritura. En su introducción, Schimigalle advierte que estas crónicas probablemente no fueran compiladas con anterioridad debido a que no abordan explícitamente temas de arte y 
literatura, en particular de poesía, o porque su escritura no se guiaba por el modelo clásico de la crónica de entonces, el cual se concentraba en una noticia o anécdota local que, en su desarrollo, propiciaba agudas reflexiones de valor universal. Sin embargo, que estas crónicas no se hayan ajustado al canon modernista les dota de un particular interés, pues no permite conocer a un Rubén Darío mucho más versátil estilísticamente y nada ajeno a los avatares históricos y sociales que le tocó vivir. De esta manera, Schimigalle reconoce crónicas impresionistas, articuladas en su mayoría por fragmentos de temas varios, pero que en el conjunto de la crónica cobra una lectura calidoscópica. Están también las denominadas de salón, en la que descubrimos a Darío, por lo general y salvo excepciones, desencantado de la oferta plástica parisina ofrecida por la Société des Artistes Français, la Société Nationale des Beaux-Arts y la Société des Artistes Indépendants. No menos interesantes hallamos las crónicas que tienen como estructura básica la entrevista, subgénero de la crónica según Schimigalle. Valioso aporte, a nuestro entender, va que propone recrear una noticia a través de la mirada de otro, quien a su vez es mirado, cotejado y recreado por el entrevistador. Así, tenemos las miradas recreadas de Alejandro Sawa, Max Nordau, un cónsul argentino de nombre Enrique Carlos Hayton, entre otros personajes cercanos a Rubén Darío. Otras de estas crónicas desconocidas se concentran en polémicas, todas ellas vinculadas a la vigencia o no del modernismo y sus rutas a seguir. Entre los demás textos recogidos aquí, se nos ofrecen las reseñas de libros, de autores variados y en distintas lenguas, que en algunos casos, Schimigalle prefiere llamar «especie de divagaciones». Todo ello muy acorde, por cierto, con la versatilidad que ofrecía la crónica, y más en aquella época de diversidad, crisis y búsqueda de la identidad latinoamericana a través de un nuevo lenguaje, el modernista.

\section{Ricardo SUMALAVIA}

Isabelle Tauzin, El otro curso del tiempo. Una interpretación de Los ríos profundos. - Lima, edición de IFEA y Lluvia editores, 2007, 228 p. : bibliografía. - ISBN 978-9972-623-53-0.

El libro que publica Isabelle Tauzin, invita al lector a un desciframiento e interpretación de Los ríos profundos, desde la perspectiva de la articulación del tiempo.

La obra de Arguedas, a pesar de los interesantes estudios de Lienhard, Cornejo Polar y otros, sigue ofreciendo motivos de análisis debido a la compleja red de relaciones entre el relato ficcional, el mito, la música 